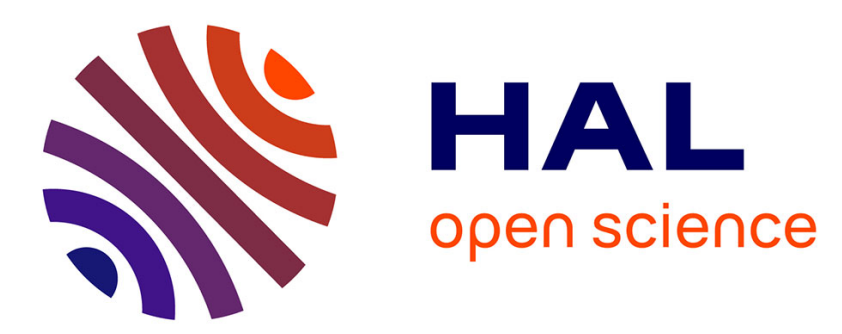

\title{
Phosphorylation of human enhancer of filamentation (HEF1) on serine 369 induces its proteasomal degradation
}

\author{
Virginie Hivert, Josiane Pierre, Joël Raingeaud
}

\section{To cite this version:}

Virginie Hivert, Josiane Pierre, Joël Raingeaud. Phosphorylation of human enhancer of filamentation (HEF1) on serine 369 induces its proteasomal degradation. Biochemical Pharmacology, 2009, 78 (8), pp.1017. 10.1016/j.bcp.2009.06.005 . hal-00514599

\author{
HAL Id: hal-00514599 \\ https://hal.science/hal-00514599
}

Submitted on 3 Sep 2010

HAL is a multi-disciplinary open access archive for the deposit and dissemination of scientific research documents, whether they are published or not. The documents may come from teaching and research institutions in France or abroad, or from public or private research centers.
L'archive ouverte pluridisciplinaire HAL, est destinée au dépôt et à la diffusion de documents scientifiques de niveau recherche, publiés ou non, émanant des établissements d'enseignement et de recherche français ou étrangers, des laboratoires publics ou privés. 


\section{Accepted Manuscript}

Title: Phosphorylation of human enhancer of filamentation (HEF1) on serine 369 induces its proteasomal degradation

Authors: Virginie Hivert, Josiane Pierre, Joël Raingeaud

PII:

S0006-2952(09)00474-2

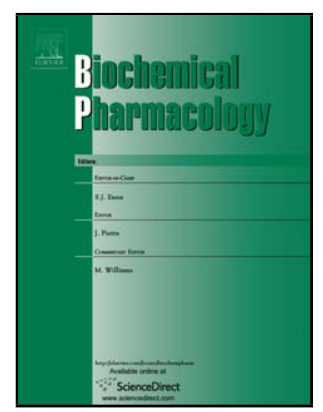

DOI: doi:10.1016/j.bcp.2009.06.005

Reference: BCP 10214

To appear in:

$B C P$

Received date:

3-3-2009

Revised date: 29-5-2009

Accepted date: 5-6-2009

Please cite this article as: Hivert V, Pierre J, Raingeaud J, Phosphorylation of human enhancer of filamentation (HEF1) on serine 369 induces its proteasomal degradation, Biochemical Pharmacology (2008), doi:10.1016/j.bcp.2009.06.005

This is a PDF file of an unedited manuscript that has been accepted for publication. As a service to our customers we are providing this early version of the manuscript. The manuscript will undergo copyediting, typesetting, and review of the resulting proof before it is published in its final form. Please note that during the production process errors may be discovered which could affect the content, and all legal disclaimers that apply to the journal pertain. 


\section{Phosphorylation of human enhancer of filamentation (HEF1) on serine 369 induces its}

\section{proteasomal degradation}

\section{Virginie Hivert $^{\mathrm{a}}$, Josiane Pierre ${ }^{\mathrm{a}}$, Joël Raingeaud ${ }^{\mathrm{a}, *}$}

${ }^{a}$ INSERM U749, Université Paris-sud 11, Faculté de Pharmacie, 92296 Chatenay-Malabry, France

*Corresponding author. INSERM U749, Faculté de Pharmacie, 5, rue JB Clement, 92296

Chatenay-Malabry France. Tel.: +331468354 49 fax : +3314683 5496.

E-mail address: joel.raingeaud@u-psud.fr(J. Raingeaud).

\section{ABSTRACT}

Human enhancer of filamentation 1 (HEF1) is a multi-domain docking protein of the p130 Cas family. HEF1 is present at focal adhesions and is involved in integrin signalling mediating cytoskeleton reorganization associated with cell migration, adhesion or apoptosis. HEF1 functions are regulated in part by phosphorylation on tyrosine residues. HEF1 is also phosphorylated on serines/threonines leading to two isoforms refered to as p105 and p115. In most cases, the serine/threonine kinase(s) responsible for HEF1 phosphorylation have not been identified. In the present study, we have investigated HEF1 ser/thr phosphorylation. In the HCT-116 cell line transiently overexpressing Flag-HEF1 we showed that Hesperadin, a synthetic indolinone displaying antiproliferative effect and described as an inhibitor of various kinases including Aurora-B, prevented HEF1 phosphorylation induced by the ser/thr phosphatase PP2A inhibitor : okadaic acid (OA). In addition we showed that conversion of endogenous HEF1 p105 to p115 in HaCaT cells was prevented upon treatment with Hesperadin, resulting in accumulation of p105HEF1. We also identified serine 369 as the target site of phosphorylation by this Hesperadin-inhibited kinase in HCT-116. Finally, we 
provide evidence that phosphorylation on serine 369 but not phosphorylation on serine 296 , triggers HEF1 degradation by the proteasomal machinery. These data suggest that conversion of p105 to p115 results from a ser-369-dependent phosphorylation mediated by an Hesperadin-sensitive kinase and regulates the half-life of HEF1.

Keywords: human enhancer of filamentation 1, protein phosphatase 2A, Hesperadin, protein stability.

\section{Introduction}

HEF1 (Human enhancer of filamentation 1), also known as Cas-L or NEDD9, belongs to the p130 Cas multi-domain docking protein family containing a N-terminal $\mathrm{SH} 3$ domain, numerous SH2 binding sites in a "substrate domain", a serine rich domain and a HLH motif in the $\mathrm{C}$ terminus [1]. HEF1 was first identified by complementation assay for its ability to induce pseudohyphal growth in S. Cerevisiae [2]. Later on, its role in intracellular signalling and regulation of cytoskeleton has been further characterized. Several reports demonstrated that HEF1 is mainly expressed in lymphoid and epithelial cells [2, 3]. It has been implicated in signalling pathways initiated by ligation of integrins or antigen on BCR or TCR [2-5]. Moreover HEF1 is localized to focal adhesion sites where its interaction with various partners is regulated by phosphorylation on tyrosine residues by kinases of the FAK and Src families $[6,7]$. Phospho-tyrosine residues become docking sites for $\mathrm{SH} 2$ domain containing proteins such as CrkL, mediating the activation of small G proteins including Cdc42, Rap1 and RhoA [8-12]. These effectors link HEF1 to regulation of cell morphology, cytoskeleton reorganization and regulation of adhesion $[1,13]$. HEF1 invalidation in mouse leads to B cells migration defects [14]. Furthermore, the increase in HEF1 expression in melanoma metastasis 
compared to primary melanomas supports a contribution of this protein to motility and invasiveness [15].

HEF1 is also regulated by proteasomal degradation. In the TGF $\beta$ signalling pathway, HEF1 interacts with Smad3 and is consequently targeted to the proteasome through an APC/CDH1 dependent mechanism [16, 17]. Alternatively, the Atrophin-1 Interacting Protein4 (AIP-4) has been proposed as an ubiquitin E3 ligase in Smad3-HEF1 degradation induced by TGF $\beta$ [18]. Different studies have reported that proteasomal degradation of HEF1 affects preferentially the serine/threonine phosphorylated form of HEF1 refered to as p115 [16, 19].

Phosphorylation of HEF1 on serine/threonine residues and appearance of the p115 isoform have been described as a result of cell adhesion [20, 21]. However, the serine/threonine kinase(s) responsible for this HEF1 phosphorylation have not been identified in most cases. A recent study has described the phosphorylation of serine 296 of HEF1 by the cell-cycle-dependent kinase Aurora-A [22]. Several reports pointed out a tyrosine dephosphorylation of the components of the focal adhesion complex including FAK, paxillin and p130 Cas associated with ser/thr phosphorylation of these proteins and the dissociation of the complex during the $\mathrm{M}$ phase of the cell cycle. This suggests that focal adhesion protein interaction is linked to ser/thr phosphorylation status [23, 24].

Aurora-A is a member of Aurora kinase family that includes three members, Aurora-A, $-\mathrm{B}$ and $-\mathrm{C}$. All of them are regulators of mitosis and Aurora-A and -B are overexpressed in a variety of tumor cell lines suggesting a role in tumorigenesis [25]. Aurora-A is implicated in mitotic entry, centrosome maturation and spindle assembly. In contrast, Aurora-B ensures correct chromosome alignment and subsequent segregation at the level of kinetochore and progression of cytokinesis [26-28]. Aurora-A activity is down-regulated by dephosphorylation of the threonine 288 by the ser/thr phosphatase PP1 [29]. HEF1 interaction with Aurora-A leads to activation of the kinase while phosphorylated HEF1 fate is still unclear [22]. Aurora- 
$\mathrm{B}$ binds to and is negatively regulated by both PP1 and PP2A and is therefore activated by okadaic acid (OA), an inhibitor of these phosphatases [30]. Hesperadin, described as an inhibitor of Aurora-B kinase is a synthetic indolinone which displays antiproliferative properties and has entered phase I clinical trials as anti-cancer drug. In human cells, Hesperadin treatment prevents phosphorylation of Aurora-B substrates and induces a phenotype similar to Aurora-B siRNA transfection [31]. Hesperadin activity on Aurora-A has not been formally tested.

In the present study, we have further investigated HEF1 phosphorylation. We demonstrate that HEF1 is phosphorylated by a kinase sensitive to Hesperadin and identify serine 369 as the target site of phosphorylation. In addition, we provide evidence that phosphorylation on this residue regulates HEF1 degradation by the proteasomal machinery.

\section{Materials and methods}

\subsection{Cell culture}

All cell lines were obtained from ATCC unless specified. SW480 cells are derived from a primary colorectal tumor, they were cultured in Dulbecco's modified Eagle's medium (DMEM) supplemented with antibiotics (50 $\mu \mathrm{g} / \mathrm{ml}$ penicillin, $50 \mu \mathrm{g} / \mathrm{ml}$ streptomycin), with 1 $\mathrm{mM}$ sodium pyruvate and $10 \%$ fetal calf serum $(\mathrm{FCS})$ at $37^{\circ} \mathrm{C}$ with $5 \% \mathrm{CO}_{2}$. The human keratinocyte cell line $\mathrm{HaCaT}$ was obtained from N. Fusenig and maintained in the same medium. The colon cancer cell line HT-29 and the lymphopoietic Kit225 cell line were cultured in RPMI 1640 medium with antibiotics as above, with $1 \mathrm{mM}$ sodium pyruvate and 10\% FCS. The colon cancer cell line HCT-116 was cultured in McCoy's 5A medium with antibiotics as above and $10 \%$ FCS. 


\subsection{Reagents and antibodies}

Mg-132, Okadaic acid and PP2 were from Calbiochem and were added to the culture medium at final concentration of $10 \mu \mathrm{M}, 125 \mathrm{nM}$ and $10 \mu \mathrm{M}$ respectively. U0126 was from Promega and used at final concentration of $10 \mu \mathrm{M}$. Hesperadin and ZM447439, two inhibitors of Aurora-B $[31,32]$ were kindly provided by N. Kraut (Boehringer Ingelheim, Austria) and N. Keen (Astra Zeneca, Cheshire, UK) and used at final concentration of $1 \mu \mathrm{M}$ and $10 \mu \mathrm{M}$ respectively. Cycloheximide and Nocodazole were from Sigma and used at final concentration of $70 \mu \mathrm{M}$ and $300 \mathrm{nM}$ respectively. Time-course established $8 \mathrm{~h}$ as optimal time for okadaic acid treatment, Mg-132 or Hesperadin were added at the same time, in each case. Anti-HEF1 (IQ297) monoclonal antibody was from Immuquest (1/6000). Anti-Flag M2 monoclonal antibody was from Sigma (1/1000). Anti-BubR1 monoclonal antibody was from BD Biosciences (1/1000). Anti-Hsp90 monoclonal antibody was from Stressgen (1/1000). Anti-Aurora-A monoclonal antibody was from Sigma (1/10000). Anti-Aurora-B polyclonal antibody was from Abcam (1/1000).

To generate HEF1 Ser-369 phospho-specific antibody (anti-PhosphoSer-369HEF1), polyclonal rabbit antisera were collected after immunization with the phosphorylated peptide CSRDLVDGINRLpSFSST and subjected to affinity purification (procedure implemented by Covalab, Lyon, France).

\subsection{Plasmids and mutations}

The construct encoding Flag-HEF1 was generated as follows. HEF1 cDNA was amplified by RT-PCR with a forward primer: 5'-TCCCCCGGGACCGCTGCCGAAATGAAGTAT-3' and 
a reverse primer 5'-CCGCTCGAGGAACGTTGCCATCTCCAGCA-3'. PCR product was then digested with Sma I and Xho I and inserted to the Bgl II/filled in and Xho I sites of the pCMV-Tag1 vector. pCMV-Flag-HEF1 S296A, pCMV-Flag-HEF1 S369A and pCMV-FlagHEF1 S296/369A were created by using oligonucleotide-directed PCR mutagenesis to create a Ser $\rightarrow$ Ala change at amino-acid 296, or 369, or both, of full-length HEF1; these constructs are otherwise identical to pCMV-Flag-HEF1 wt (wild-type), assessed by DNA sequencing.

\subsection{Transfection experiments}

For transient transfection of HEF1 or its mutants, cells were seeded in 6-well dishes $24 \mathrm{~h}$ before transfection. The different plasmids were adjusted to $2.5 \mu \mathrm{g}$ of DNA and $7.5 \mu$ lof Jet$\mathrm{PEI}^{\mathrm{TM}}$ solution (Polyplus transfection, Illkirch, France). After $24 \mathrm{~h}$ incubation, cells were supplemented with fresh culture medium and left untreated or incubated with the various reagents, as indicated.

\subsection{Preparation of cell lysates and Western-Blot analysis}

Cells were washed twice with ice-cold PBS buffer and solubilized with lysis buffer $(20 \mathrm{mM}$ Tris-HCl, $\mathrm{pH}$ 7.4, $137 \mathrm{mM} \mathrm{NaCl,} 2$ mM EDTA, pH 7.4, 1\% Triton-X100, 2 mM sodium pyrophosphate, $10 \%$ glycerol, $25 \mathrm{mM}$ sodium $\beta$-glycerophosphate, $1 \mathrm{mM}$ sodium orthovanadate, $1 \mathrm{mM}$ phenylmethysulfonyl fluoride, $10 \mu \mathrm{g} / \mathrm{mL}$ leupeptin and $10 \mu \mathrm{g} / \mathrm{mL}$ aprotinin). After incubation on ice for 20 minutes, cell extracts were centrifuged at $15000 \mathrm{x} \mathrm{g}$ for $20 \mathrm{~min}$ at $4^{\circ} \mathrm{C}$. The protein concentration of cell extracts was determined using a $\mathrm{BCA}$ protein assay reagent (Sigma). Aliquots of cell lysates containing equal amount of protein were subjected to SDS-PAGE under reducing conditions, transferred to a Hybond-C 
nitrocellulose membrane (Amersham Bioscience) and probed with appropriate antibodies. Immunocomplexes were detected using enhanced chemiluminescence (Amersham, GE Healthcare)

\subsection{Small interfering RNA and transfection}

The Aurora-A and -B small interfering RNA (siRNA) sequences used have been described previously and are as follows : 5'-AUGCCCUGUCUUACUGUCA-3' (Aurora-A) and 5'GGUGAUGGAGAAUAGCAGU-3' (Aurora-B) [31, 33]. Briefly, 10 or 20 pmol of siRNA and $20 \mu 1$ of Interferin (Ozyme) were added to $200 \mu 1$ of Opti-MEM (Invitrogen), mixed gently, and then incubated for 10 minutes at room temperature. After incubation, the mixture was added to the plate $\left(9 \mathrm{~cm}^{2}\right)$ in $800 \mu \mathrm{L}$ of DMEM plus $10 \%$ FCS and left for 48 hours before lysis for protein analysis.

\subsection{Immunoprecipitation}

Cell lysates (500 $\mu$ g-aliquots) prepared as above, were incubated with $4 \mu \mathrm{g}$ of antibody for $2 \mathrm{~h}$ at $4^{\circ} \mathrm{C}$. Next, $40 \mu \mathrm{L}$ of protein G-sepharose beads (GE Healthcare) were added, and reaction mixtures were incubated $45 \mathrm{~min}$ at $4^{\circ} \mathrm{C}$. The immunoprecipitates were washed three times with lysis buffer.

\subsection{In vitro dephosphorylation assay}


Lysates were immunoprecipitated as described above. The immunoprecipitates were then washed three times with calf intestinal alcaline phosphatase (CIAP) buffer (50 mM Tris- $\mathrm{HCl}$, $\mathrm{pH} 8.5,0.1 \mathrm{mM}$ EDTA) and incubated with $10 \mathrm{U}$ of CIAP (Invitrogen) for $1 \mathrm{~h}$ at $37^{\circ} \mathrm{C}$.

\section{RESULTS}

\subsection{HEF1 is differentially expressed in various cells}

HEF1 mRNA expression is cell type specific, the transcript being mainly present in epithelial and lymphoid cells. We first evaluated HEF1 protein expression in different cell lines including Kit225, HaCaT, SW480, HCT-116 and HT-29. Depending on the cell type tested, HEF1 was either weakly or not expressed, present as a single band (105 kDa) or detected as a doublet (105 and $115 \mathrm{kDa}$ ) (Fig. 1). This two bands profile (p105 \& p115) is a product of 2 different ser/thr phosphorylation states of HEF1, previously described in the litterature [20, 21]. We then decided to examine the significance of this difference.

\subsection{Okadaic acid induces serine/threonine phosphorylation of HEF1}

As we did not observe any expression of HEF1 in HCT-116 cell line, we decided to further investigate HEF1 phosphorylation in these cells by transfecting them with a Flag-tagged HEF1. As shown in Fig. 2A, in HCT-116 cells, ectopic Flag-HEF1 is expressed as a single band. PP2A has been described as a phosphatase regulating HEF1 phosphorylation in fibroblast cells [19]. We performed a time-course treatment with okadaic acid (OA), an inhibitor of the serine/threonine phosphatases PP2A and PP1, on these cells and examined HEF1 migration profile after separation on SDS-PAGE using an acrylamide/bisacrylamide 
ratio of 30:0.2 which improves the separation of ser/thr phosphorylation-induced gel shifts. While in the control cells, HEF1 is expressed as a single band (Fig. 2A, band a), inhibition of PP2A reveals a slower migrating band after 3 hours (band b), followed by a third band after 5 hours (band c).

We hypothesized that this migration profile resulted from HEF1 ser/thr phosphorylation. We then performed an in vitro dephosphorylation assay of ectopic HEF1 immunoprecipitated from cells treated with OA for 8 hours. As shown in Fig. 2B, the phosphatase treatment totally abolished slower migrating forms. This data indicates that the two slower migrating forms are the products of at least two phosphorylated states of HEF1 on serine or threonine residues.

\subsection{HEF1 is phosphorylated in vivo by an Hesperadin-sensitive kinase}

It has been reported that HEF1 phosphorylation is cell cycle-regulated and that HEF1 is a substrate for Aurora-A kinase [22]. The above experiment showed that OA treatment revealed at least two different states of phosphorylation of HEF1. Moreover, OA has also been described as an activator of Aurora kinases A and B [29, 30]. To examine the involvement of the Aurora kinases in HEF1 phosphorylation, we transiently transfected HCT-116 cells with Flag-HEF1 and incubated them with OA alone or in the presence of Hesperadin, an inhibitor of Aurora-B kinase. As shown in Fig. 3, co-incubation with OA and Hes resulted in the disappearance of the slower migrating band from the 3 bands pattern of migration of HEF1 visualized upon OA treatment alone. This result strongly suggests that the presence of this particular band (band c) depends on the activity of a kinase that is sensitive to Hesperadin. In contrast, treatment with Hesperadin did not affect the level of band $b$. This data indicates that other kinase(s) not sensitive to Hesperadin is (are) also involved in OA-induced HEF1 
phosphorylation. In parallel, other inhibitors of cell cycle-regulated kinases such as olomoucin or scytonemin failed to prevent OA-induced HEF1 phosphorylation shift (data not shown). We checked the inhibition properties of Hes in our cells by looking for the phosphorylation of a specific Aurora-B substrate : the checkpoint protein kinase BubR1 [32]. Upon 8 hours incubation with OA, BubR1 is phosphorylated (visualized by the presence of slower migrating forms) (Fig. 3, lower panel). When OA and Hes were added concomitantly, BubR1 shifts in migration profile were not detected anymore. This indicates that the OA-induced BubR1 migration shift is sensitive to Hesperadin. Thus in these cells, OA effectively increases the phosphorylation of Aurora-B substrates. Taken together, these results indicate that Aurora-B could be the kinase able to phosphorylate HEF1 in HCT-116 cells.

\subsection{An Hesperadin-sensitive kinase phosphorylates HEF1 on serine 369}

Serine 296 of HEF1 has been described as a target amino acid for Aurora-A phosphorylation [22]. In addition, the examination of the primary sequence of the protein revealed the existence of an R-X-S located at serine 369 matching the consensus phosphorylation site for Aurora-B but also for other kinases which may be inhibited by Hesperadin [31]. We generated various Flag-tagged HEF1 mutants lacking one or both of these two potential phosphorylation sites. The mutants were overexpressed in HCT-116 cells, and cells were treated or not with OA. The Flag-tagged HEF1 mutant S369A (serine 369 replaced by alanine) does not migrate similarly to wild-type HEF1 after OA treatment (Fig. 4A, lane 1), but exhibits only two bands (lane 2). This two-bands pattern seems to be similar to the one observed previously with wildtype HEF1 upon OA/Hes co-treatment (band a and b, Fig. 3) suggesting that S369A point mutation abolished the OA induced phosphorylation inhibited by Hes. Upon OA treatment, the Flag-tagged HEF1 mutant S296A (serine 296 replaced by alanine) migrated differently, 
displaying the basal form (band a) and a shifted protein migrating between the two slower migrating bands observed with the wild-type HEF1 (asterisk indicates the position of band d in lane 3). The Flag-tagged HEF1 double-mutant S296/369A is no longer shifted after OA treatment. Therefore, band d seems to be the signature of a single phosphorylation on serine 369. Thus band a corresponds to the basal isoform of HEF1, bands $b, d$ and c correspond to the shifts induced by HEF1 phosphorylation on ser-296, ser-369 and ser-296 \& 369 respectively.

To confirm the involvement of the Hesperadin-sensitive kinase in the phosphorylation of ser-369 but not of ser-296, HCT-116 cells were transfected with the two single mutants of HEF1 and incubated with OA alone or in combination with Hes. As expected, Hes has no effect on OA-induced ser-296 phosphorylation shift (Fig. 4B, upper panel), but totally abolished OA-induced ser-369 phosphorylation shift (Fig. 4B, lower panel). Of note, in this experiment band $\mathrm{c}$ is not detected as no double phosphorylation occurred.

In order to ascertain that mutation of serine 369 does not prevent phosphorylation of a different residue in HEF1 but is the actual amino acid phosphorylated, we raised an antibody against an HEF1 peptide encompassing phosphorylated Ser-369. The antibody obtained gave good immuno-reactivity on Western blot. As shown on Fig. 6C lane 1 and 2, all the bands (a, b, c and d) described earlier are detected with the M2 antibody. However, only band c from wild type HEF1 and band d from S296A HEF1 are detected with the anti-PhosphoSer-369HEF1 antibody (Fig. 6C lane 5 and 6). This result confirms that Serine 369 is the amino acid phosphorylated upon OA treatment.

Overall, these results indicate that in cells, ectopically expressed HEF1 is phosphorylated on both serines 296 and 369 following OA stimulation and that serine 369 phosphorylation is dependent on a kinase inhibited by Hesperadin. These two 
phosphorylations seem to occur independently (Fig. 4A) and with different kinetics, phosphorylation of ser-369 being delayed compared to ser-296 phosphorylation (Fig. 2A).

\subsection{HEF1 stability is modulated through phosphorylation of serine 369}

Several reports show that HEF1 expression is regulated at the post-transcriptional level [16]. In order to assess the stability of exogenous HEF1 in HCT-116 cells, we performed a timecourse treatment with cycloheximide (CHX), an inhibitor of protein synthesis. As shown in Fig. 5A (top left panel), in HCT-116 cells, in the presence of CHX a decrease in HEF1 protein level occurred, pointing out the short half-life of this protein as previously described in other cell lines [21]. We have shown that HEF1 is phosphorylated on ser-369. We then investigated whether in HCT-116 cells, HEF1 degradation is regulated by its phosphorylation on serine 369 by using Hesperadin. As shown on Fig. 5A (top right panel), the decrease in HEF1 is delayed in the presence of Hes, compared to the control time-course. Bands intensities were quantified by densitometric analysis (Fig. 5A bottom panel). Hesperadin strongly increased the stability of HEF1 which indicates that HEF1 instability depends on its phosphorylation by the Hesperadin-sensitive kinase.

To evaluate which serine phosphorylation promotes HEF1 instability, we transiently transfected HCT-116 cells with the HEF1 single and double mutants and CHX was added to the medium for different periods of time (from 2 to 10 hours). Compared to wild-type HEF1, virtually no degradation of the S369A mutant of HEF1 was observed even after $10 \mathrm{~h}$ of CHX treatment (Fig. 5B, top right panel). This suggests that ser-369 phosphorylation triggers HEF1 degradation. By contrast, the same experiment performed with the HEF1 mutant S296A shows a degradation pattern similar to the one observed with wild-type HEF1, indicating that HEF1 degradation occurs independently of the phosphorylation state of serine 296 (Fig. 5B, 
top left panel). Finally, the double-mutated HEF1 behaves like HEF1 mutant S369A which agrees with a contribution of ser-369 phosphorylation in instability of HEF1 protein (Fig. 5B, bottom panels).

\subsection{Phosphorylation of HEF1 on serine 369 induces its proteasomal degradation}

To determine how HEF1 was degraded in our model, we performed the same time-course treatment with $\mathrm{CHX}$ on Flag-HEF1 transfected HCT-116 cells as in Fig. 5A, but Mg-132, a proteasome inhibitor was added to the medium concomitantly to $\mathrm{CHX}$ (Fig. 6A). We observed very little degradation of ectopic wild-type HEF1 in these conditions, suggesting that its degradation occurs through a proteasomal mechanism. Moreover, when Flag-HEF1 transfected HCT-116 cells were incubated for 8 hours with Mg-132 only (without OA) and HEF1 immunoprecipitated from the cell lysates, we were able to detect a slower migrating band (marked by an asterisk, Fig. 6B, compare lane 1 and 2) which may correspond to a ser/thr phosphorylated form of HEF1 identical to the one observed on Fig. 4A, lane 3 (refered to as band d). Moreover, the additional HEF1 species observed with Mg-132 is no longer detectable when cells were treated concomitantly with Hesperadin (Fig. 6B, compare lane 2 and 3), which indicates that this additional species might be a product of the Hesperadin inhibited kinase activity. Altogether, these results suggest that HEF1 phosphorylation on ser369 by the Hesperadin-sensitive kinase triggers its proteasomal degradation.

We next evaluated the effect of Mg-132 on the different mutant forms of HEF1. Wildtype HEF1 protein or mutated forms were overexpressed in HCT-116 cells. Cells were stimulated either with OA or Mg-132 or both. Compared to OA alone, addition of Mg-132 leads to an increase in intensity of both double phosphorylated isoform of wild-type HEF1 and shifted band of S296A HEF1 reflecting a stabilization of these HEF1 isoforms (Fig. 6C, 
compare lane 3 versus 2). This suggests that phosphorylation of serine 369 renders HEF1 more sensitive to proteasomal degradation. By contrast, phosphorylation of serine 296 does not modulate HEF1 susceptibility to proteasomal degradation (S369A panel).

In order to confirm that the proteasome inhibitor stabilized HEF1 isoform phosphorylated on ser-369 we performed a Westernblot with the anti-PhosphoSer369HEF1 antibody. As shown in Fig. 6C lane 7, Mg-132 treatment dramatically increased the stability of wild type HEF1 phosphorylated on both ser-296 and ser-369 (band c) and S296A HEF1 phosphorylated on ser-369 (band d) (compare lane 6 and 7). As a control, no signal was observed with the S369A HEF1 and S269/369A HEF1 mutants treated with $\mathrm{OA}$ and Mg-132.

\subsection{Endogenous HEF1 is stabilized by Hesperadin treatment}

In the following set of experiments, we checked whether the stability of endogenous HEF1 in HaCaT cells depends on its phosphorylation. We performed a time-course treatment with CHX or Hes or Mg-132 on HaCaT cells. Fig. 7A shows that both HEF1 isoforms p105 and p115 disappear upon CHX treatment confirming the instability of endogenous HEF1 in HaCaT cells. Hesperadin addition dramatically increased the intensity of p105HEF1 while we observed a moderate accumulation of p1 15 (Fig. 7B). This data indicates that, in HaCaT cells, Hes inhibits the conversion of p105 to p115 resulting in an accumulation of p105HEF 1. Finally, upon Mg-132 treatment of HaCaT cells, we observed an increase of both p105 and p115 but the intensity is more pronounced for p115HEF1 (Fig. 7C). This result suggests that inhibition of proteasomal machinery decreases the degradation of p115 and to a lesser extent of p105. Taken together, these results indicate that, in HaCaT cells, conversion of p105 to p115 is dependent on phosphorylation and that inhibition of this phosphorylation by 
Hesperadin stabilizes HEF1 by removing this protein from proteasomal degradation pathways.

\subsection{Aurora-B kinase is not involved in HEF1 ser-369 phosphorylation}

Finally, we sought to determine whether Aurora-B was the kinase responsible for HEF1 phosphorylation and therefore conversion of p105 to p115. For this, we transfected HaCaT cells with siRNA for Aurora-B, and Aurora-A as a control and analyzed endogenous HEF1 migration profile. As expected transfection of these siRNA leads to depletion of either Aurora-A and -B (Fig. 8A). However inhibition of Aurora-B kinase expression does not correlate with increase of p105 band intensity. This result suggests that the Hesperadinsensitive kinase responsible for HEF1 phosphorylation may not be Aurora-B. In order to confirm the actual inhibition of Aurora-B kinase activity, we analyzed the phosphorylation status of an Aurora-B substrate (BubR1) following Aurora-B siRNA transfection of HaCaT cells and treatment with Nocodazole, which blocks the cell cycle at M phase when Aurora-B is activated. As shown in Fig. 8B, Aurora-B siRNA transfection dramatically decreases Aurora-B expression; however, in the presence of Nocodazole BubR1 phosphorylation still occurs suggesting that even though it is expressed at a low level, enough protein is present to ensure BubR1 phosphorylation. We then tested another Aurora kinase inhibitor: ZM447439, which has been shown to target both Aurora-A and -B [32]. Surprisingly, compared to Hesperadin, ZM447439 does not inhibit HEF1 phosphorylation shift (Fig. 8C). As a control, cells were treated with Nocodazole to induce phosphorylation of Aurora-B substrate BubR1. Both inhibitors were able to prevent Nocodazole-induced BubR1 phosphorylation shift while in the same lysate, only Hesperadin inhibits HEF1 phosphorylation shift (Fig. 8C). These 
results indicate that Aurora-B is not the Hesperadin-sensitive kinase which triggers conversion of p105HEF1 to p115HEF1.

However, while Hesperadin is widely used as an Aurora-B inhibitor, several other kinases are also inhibited in vitro by Hesperadin, namely, AMP dependent kinase AMPK, the lymphocyte tyrosine kinase Lck, the MAPKK Mek1, the Erk substrate MAPKAPK1/p90Rsk, the checkpoint kinase Chk1 and the phosphorylase kinase PHK [31]. The potential contribution of most of these kinases in HEF1 phosphorylation has been examined. We used pharmacological inhibitors of Src (PP2) and Mek1 (U0126) which inhibits Erk1 substrate MAPKAPK1 activation as well. As shown in Fig. 8D, neither U0126 nor PP2 prevent conversion of p105 to p115, although in the mean time, PP2 seems to decrease HEF1 expression (Fig. 8D). Moreover, we did not observe HEF1 shift inhibition in Chk1 siRNA transfected HaCaT cells and in mouse embryo fibroblasts invalidated for AMPK $\alpha 1 / 2$ compared to wild type MEF (data not shown).

Altogether, these data suggest that conversion of HEF1 p105 to p115 in HaCaT cells occurs via an Hesperadin-sensitive phosphorylation which is independent of Aurora-B kinase.

\section{Discussion}

HEF1 is a docking protein present at focal adhesions and phosphorylated on tyrosine residues upon integrin binding, which links focal adhesion to cytoskeleton [1]. However, HEF1 is also phosphorylated on serine and threonine residues; indeed, HEF1 appears as a doublet: p105 and p115 (105 and $115 \mathrm{kDa}$ ) which mirrors two different phosphorylation states of the protein $[20,21]$. In this study we investigated the ser/thr phosphorylation of HEF1 in cells. In HCT116, over-expressed HEF1 protein is detected as a single band. However, depending on conditions, when HEF1 is immunoprecipitated we were able to detect the p115 isoform 
with proteasome inhibitor (Fig. 6B lane 2). So both isoforms seem to be present in these cells but for unknown reason, owing to the ectopic character of the protein (and maybe the fact that it was Flag-tagged), HEF1 is either less subject to phosphorylation or more rapidly degraded in $\mathrm{HCT}-116$ cells.

We showed that conversion to p115HEF1 is a result of phosphorylation of p105 by a Hesperadin-inhibited kinase and we identified ser-369 of HEF1 as the target residue of this kinase. We confirmed, using an anti-PhosphoSer-369HEF1 that serine 369 is indeed the residue targeted by this kinase. Moreover, our experiments also suggest that phosphorylation of HEF1 on ser-369 does not appear to depend upon either Aurora-A or Aurora-B kinase activity. So far, only the Aurora-A kinase was identified as an HEF1 kinase in MCF-7 cells, targeting ser-296. HEF1 interaction with Aurora-A during mitosis leads to kinase activation and its dissociation from phosphorylated HEF1 [22].

Two studies suggested that adhesion of Y1F cells induced ser/thr phosphorylation of HEF1 (conversion of p105 to p1 15 isoform) through a mechanism involving PP2A-dependent inhibition $[19,21]$. Such a regulation of phosphorylation did not occur in HaCaT cells (data not shown). Using the PP2A inhibitor, okadaic acid, we have been able to discriminate two serine phosphorylations on HEF1 (ser-296 and ser-369) occurring independently and with different kinetics (Fig. 2A \& 4A). Mutation of these residues clearly prevents HEF1 shifting (Fig. 4A). A role of PP1 and/or PP2A in regulating Aurora kinases has been described previously $[29,30]$. Autophosphorylation of a threonine residue in the kinase domain of Aurora is necessary to activate the kinases $[29,34]$. Their inactivation occurs via a PP1 and/or PP2A-dependent dephosphorylation of this threonine. Furthermore, besides Aurora-B, other target kinases of Hesperadin (AMPK, Chk1, Mek1...) are also substrates of PP2A, although at a higher $\mathrm{IC}_{50}$, which make them candidates for HEF1 phosphorylation [35-37]. Furthermore, PP2A dephosphorylates another member of HEF1 docking protein family, p130 Cas [38]. 
This suggests that PP2A might then target both protein, the Hesperadin sensitive kinase and HEF1. We therefore can not conclude as to whether increased phosphorylation of HEF1 in OA-treated HCT-116 cells results from inhibition of PP2A-mediated dephosphorylation of HEF1 or from increased kinase activity. Of note, even though we added PP2A inhibitor to observe HEF1 phosphorylation more readily, such a basal phosphorylation of HEF1 by the Hesperadin-inhibited kinase seems to actually occur even in the absence of OA treatment as observed in the presence of proteasome inhibitor without Hesperadin (Fig. 6B).

We also attempted to identify the kinase inhibitable by Hesperadin which is responsible for HEF1 phosphorylation on ser-369 and conversion of endogenous HEF1 p105 to p115. While Aurora-B was a good candidate as ser-369 matches perfectly the phosphorylation consensus site for this kinase, transfection of siRNA for Aurora-B failed to prevent HEF1 phosphorylation. In the mean time, the depletion of Aurora-B by siRNA did not prevent phosphorylation of BubR1, a known Aurora-B substrate, while Hesperadin did; indicating that Aurora-B exctinction by siRNA was not complete. However, the use of another inhibitor, ZM447439 inhibiting Nocodazole-induced BubR1 phosphorylation but not HEF1 conversion to p115 allowed us to exclude Auroras as HEF1 kinases in HaCaT cells. Moreover, Aurora-A and -B depletion in HCT-116 cells transfected with HEF1 did not prevent phosphorylation of HEF1 on ser-369 and ser-296 following OA treatment; thus confirming the results obtained on endogenous HEF1 in HaCaT cells (Fig. 8C and data not shown). Specificity of Hesperadin has already been studied. Besides Aurora-B, six other kinases turned out to be inactivated by this drug in vitro, although with different $\mathrm{IC}_{50}$. These kinases include AMPK, Chk1, Lck, Mek1, MAPKAPK1/p90Rsk and Phosphorylase Kinase PHK [31]. Use of a specific inhibitor of Mek1 and siRNA targeting Chk1 excluded the potential contribution of these kinases in HEF1 ser-369 phosphorylation. The fact that p90Rsk is a target of the Mek1/Erk pathway and thus is sensitive to Mek inhibition makes it unlikely to be the HEF1 kinase (Fig. 8D and data 
not shown). The p56 Lck, as a tyrosine kinase can not directly phosphorylate HEF1 on serine but could somehow regulate the activity of the HEF1 kinase. However the Src family kinase inhibitor PP2, known to target p56Lck [39], has no effect on the HEF1 shift. Further experiments are needed to precisely identify the kinase.

Our results also clearly showed that in $\mathrm{HaCaT}$ cells, endogenous p115HEF1 depends on an Hesperadin-sensitive phosphorylation of p105HEF1 and this isoform is targeted to the proteasome (Fig. 7). We were able to show that in HCT-116 cells, the S369A but not the S296A mutation of HEF1 increases its stability (Fig. 5B). Recent published works agree with the preferential degradation of p115HEF1 isoform [16, 18], although no kinase was identified yet. Interestingly, haematopoietic isoform of Cas/HEF1 Associated signal Transducer (CHAT-H), a binding partner of the Cas family proteins, is required to induce ser/thr phosphorylation of HEF1 and N-terminal domain of CHAT-H is necessary for this phosphorylation to occur [11]. Using several inhibitors such as PKC, Mek, PDK, PI3K inhibitors the authors failed to identify the kinase responsible for HEF1 ser/thr phosphorylation. Moreover, in their work, they deleted a short region of the serine-rich domain of HEF1 (from ser-369 to pro-396) that removes ser-369. Such deletion mutant does not undergo ser/thr phosphorylation anymore, which is in agreement with our results. It would be interesting to check which phosphorylated residue is targeted through CHAT-H interaction with HEF1.

Several reports demonstrated that ser/thr phosphorylation of HEF1 mediates its proteasomal degradation; p115HEF1 being the main isoform interacting with Smad3 and triggering the degradation of both proteins via an APC/CDH1 pathway [16, 17]. Moreover AIP-4, an E3 ubiquitin ligase for HEF1, interacts more strongly with p115HEF1 than with the p105 isoform and ectopic expression of AIP-4 triggers preferentially p115HEF1 degradation [18]. The fact that ser-369 phosphorylated HEF1 undergoes proteasomal degradation is 
confirmed by the strong increase of this phosphorylated isoform upon Mg-132 treatment compared to OA alone (Fig. 6C). However, in the HCT-116 cell line, none of these proteins interacts with HEF1, which suggests that HEF1 degradation is not mediated through AIP-4, Smad3 or CDH1 (data not shown). In addition, besides its degradation through the proteasome, Law et al showed that upon TNFa stimulation in MCF-7 cells, HEF1 can be processed in a caspase-dependent manner [20, 40]. Although the ser-369 is very close to the $\mathrm{D}_{363} \mathrm{LVD}_{367}$ consensus caspase cleavage site, we did not observe a stabilization of this HEF1 isoform with addition of caspase inhibitor (data not shown), indicating that HEF1 clearance does not occur in a caspase dependent manner.

Finally, we showed that in $\mathrm{HaCaT}$ cells, endogenous HEF1, detected as a doublet, undergoes degradation. When expressed in these cells, ectopic Flag-HEF1 is detected as a single band as observed in HCT-116 cells; moreover ectopic expression of HEF1 in $\mathrm{HaCaT}$ cells results in the same pattern as in HCT-116 cells, upon OA and Mg-132 treatment (data not shown). Zheng \& Mc Keown-Longo demonstrated that ser/thr phosphorylated p115HEF1 is the major isoform targeted to the proteasome [19]. We showed that Hesperadin treatment leads to a dramatic increase of the p105HEF1 isoform which confirms that p105 is less sensitive to proteasomal degradation than $\mathrm{p} 115$. Moreover, we observed a moderate increase of the p115 isoform. This augmentation remains unexplained; although it is possible that the over accumulation of p105HEF1 might result in increased phosphorylation. Alternatively, there are examples of proteins in which a single residue is the target of different kinases [41, 42]. So we can not exclude that other kinase(s) phosphorylate HEF1 on ser-369 but also on another residue leading to an HEF1 isoform that would be less sensitive to degradation and would be part of the p115 band. Comparatively, proteasome inhibitor treatment leads to accumulation of p115HEF1, even though p105 also increases. Indeed, this phosphorylation/dephosphorylation of HEF1 can be considered as a dynamic process, the 
kinase and PP2A activities regulating the switch between the two isoforms. It has also been hypothesized that different pools of HEF1 may be present in different subcellular compartments and have distinct functions [43]. Pugacheva \& Golemis showed that HEF1 interacts with and activates Aurora-A during mitosis [22]. One can imagine that phosphorylation of a specific pool of HEF1 may modify the fate of this protein. In fact, Dadke et al reported that by interacting with the RhoA-GEF ECT2, HEF1 positively regulates RhoA activity during early mitosis. Late in mitosis, the cleavage furrow regression needs RhoA to be inactivated and these authors showed that down-regulation of HEF1 expression is required for the cytokinesis to progress [10]. Phosphorylation of this specific pool of HEF1 at this moment might be a way for the cell to trigger RhoA inactivation. This may also explain why Hesperadin and Mg-132 treatment do not lead to a complete disappearence of p115 or p105 respectively.

We showed that HEF1 phosphorylation increases its degradation. The coupling of HEF1 phosphorylation on ser-369 and proteasomal degradation might not be cell type specific, but rather reflects a more general mechanism. It would be interesting to explore the mechanisms underlying the difference in HEF1 isoforms expression patterns between cell types.

In conclusion, HEF1 is a downstream target of unidentified integrin-regulated ser/thr kinases but also of cell cycle dependent kinases. It is likely that more than one kinase is involved in the phosphorylation of distinct residues mediating different processes. Indeed ser/thr phosphorylation of HEF1 is required for migration [15], adhesion [21], cell cycle [22], but may lead to degradation as well [19]. According to its localization, ser/thr phosphorylated HEF1 seems to have different functions. Here we demonstrated that HEF1 is phosphorylated on ser-369 by a Hesperadin-sensitive kinase. Furthermore, we showed that HEF1 phosphorylation at this site is required for its degradation by the proteasomal machinery. 


\section{Acknowledgements}

We thank Jacques Bertoglio and Muriel David for helpful discussion and critical reading of the manuscript. We are grateful to Norbert Kraut, Nick Keen and B. Viollet for providing Hesperadin, ZM447439 and AMPKa1/2 ${ }^{-/}$MEF cells respectively. The authors were supported by the French ministry of Research fellowship for V.H. and by funds from INSERM. J.R. is a CNRS investigator.

\section{REFERENCES}

[1] O'Neill GM, Fashena SJ, Golemis EA. Integrin signalling: a new Cas $(\mathrm{t})$ of characters enters the stage. Trends Cell Biol 2000;10:111-9.

[2] Law SF, Estojak J, Wang B, Mysliwiec T, Kruh G, Golemis EA. Human enhancer of filamentation 1, a novel p130cas-like docking protein, associates with focal adhesion kinase and induces pseudohyphal growth in Saccharomyces cerevisiae. Mol Cell Biol 1996;16:3327-37.

[3] Minegishi M, Tachibana K, Sato T, Iwata S, Nojima Y, Morimoto C. Structure and function of Cas-L, a 105-kD Crk-associated substrate-related protein that is involved in beta 1 integrin-mediated signaling in lymphocytes. J Exp Med 1996;184:1365-75.

[4] Manie SN, Beck AR, Astier A, Law SF, Canty T, Hirai H, et al. Involvement of p130(Cas) and p105(HEF1), a novel Cas-like docking protein, in a cytoskeletondependent signaling pathway initiated by ligation of integrin or antigen receptor on human B cells. J Biol Chem 1997;272:4230-6.

[5] Ohashi Y, Iwata S, Kamiguchi K, Morimoto C. Tyrosine phosphorylation of Crkassociated substrate lymphocyte-type is a critical element in TCR- and beta 1 integrininduced T lymphocyte migration. J Immunol 1999;163:3727-34.

[6] van Seventer GA, Salmen HJ, Law SF, O'Neill GM, Mullen MM, Franz AM, et al. Focal adhesion kinase regulates beta 1 integrin-dependent $\mathrm{T}$ cell migration through an HEF1 effector pathway. Eur J Immunol 2001;31:1417-27.

[7] Zhang Z, Baron R, Horne WC. Integrin engagement, the actin cytoskeleton, and c-Src are required for the calcitonin-induced tyrosine phosphorylation of paxillin and HEF1, but not for calcitonin-induced Erk1/2 phosphorylation. J Biol Chem 2000;275:3721923.

[8] Astier A, Manie SN, Law SF, Canty T, Haghayghi N, Druker BJ, et al. Association of the Cas-like molecule HEF1 with CrkL following integrin and antigen receptor signaling in human B-cells: potential relevance to neoplastic lymphohematopoietic cells. Leuk Lymphoma 1997;28:65-72.

[9] Cai D, Felekkis KN, Near RI, O'Neill GM, van Seventer JM, Golemis EA, et al. The GDP exchange factor AND-34 is expressed in B cells, associates with HEF1, and activates Cdc42. J Immunol 2003;170:969-78. 
[10] Dadke D, Jarnik M, Pugacheva EN, Singh MK, Golemis EA. Deregulation of HEF1 impairs M-phase progression by disrupting the RhoA activation cycle. Mol Biol Cell 2006;17:1204-17.

[11] Regelmann AG, Danzl NM, Wanjalla C, Alexandropoulos K. The hematopoietic isoform of Cas-Hef1-associated signal transducer regulates chemokine-induced insideout signaling and T cell trafficking. Immunity 2006;25:907-18.

[12] Sattler M, Salgia R, Shrikhande G, Verma S, Uemura N, Law SF, et al. Differential signaling after betal integrin ligation is mediated through binding of CRKL to p120(CBL) and p110(HEF1). J Biol Chem 1997;272:14320-6.

[13] Fashena SJ, Einarson MB, O'Neill GM, Patriotis C, Golemis EA. Dissection of HEF1dependent functions in motility and transcriptional regulation. J Cell Sci 2002;115:99111.

[14] Seo S, Asai T, Saito T, Suzuki T, Morishita Y, Nakamoto T, et al. Crk-associated substrate lymphocyte type is required for lymphocyte trafficking and marginal zone B cell maintenance. J Immunol 2005; 175:3492-501.

[15] Kim M, Gans JD, Nogueira C, Wang A, Paik JH, Feng B, et al. Comparative oncogenomics identifies NEDD9 as a melanoma metastasis gene. Cell 2006;125:126981.

[16] Liu X, Elia AE, Law SF, Golemis EA, Farley J, Wang T. A novel ability of Smad3 to regulate proteasomal degradation of a Cas family member HEF1. Embo J 2000;19:6759-69.

[17] Nourry C, Maksumova L, Pang M, Liu X, Wang T. Direct interaction between Smad3, APC10, CDH1 and HEF1 in proteasomal degradation of HEF1. BMC Cell Biol 2004;5:20.

[18] Feng L, Guedes S, Wang T. Atrophin-1-interacting protein 4/human Itch is a ubiquitin E3 ligase for human enhancer of filamentation 1 in transforming growth factor-beta signaling pathways. J Biol Chem 2004;279:29681-90.

[19] Zheng M, McKeown-Longo PJ. Cell adhesion regulates Ser/Thr phosphorylation and proteasomal degradation of HEF1. J Cell Sci 2006;119:96-103.

[20] Law SF, Zhang YZ, Klein-Szanto AJ, Golemis EA. Cell cycle-regulated processing of HEF1 to multiple protein forms differentially targeted to multiple subcellular compartments. Mol Cell Biol 1998;18:3540-51.

[21] Zheng M, McKeown-Longo PJ. Regulation of HEF1 expression and phosphorylation by TGF-beta 1 and cell adhesion. J Biol Chem 2002;277:39599-608.

[22] Pugacheva EN, Golemis EA. The focal adhesion scaffolding protein HEF1 regulates activation of the Aurora-A and Nek2 kinases at the centrosome. Nat Cell Biol 2005;7:937-46.

[23] Yamakita Y, Totsukawa G, Yamashiro S, Fry D, Zhang X, Hanks SK, et al. Dissociation of FAK/p130(CAS)/c-Src complex during mitosis: role of mitosisspecific serine phosphorylation of FAK. J Cell Biol 1999;144:315-24.

[24] Young MR, Kolesiak K, Meisinger J. Protein phosphatase-2A regulates endothelial cell motility and both the phosphorylation and the stability of focal adhesion complexes. Int J Cancer 2002;100:276-82.

[25] Bolanos-Garcia VM. Aurora kinases. Int J Biochem Cell Biol 2005;37:1572-7.

[26] Andrews PD, Knatko E, Moore WJ, Swedlow JR. Mitotic mechanics: the auroras come into view. Curr Opin Cell Biol 2003;15:672-83.

[27] Carmena M, Earnshaw WC. The cellular geography of aurora kinases. Nat Rev Mol Cell Biol 2003;4:842-54.

[28] Ducat D, Zheng Y. Aurora kinases in spindle assembly and chromosome segregation. Exp Cell Res 2004;301:60-7. 
[29] Walter AO, Seghezzi W, Korver W, Sheung J, Lees E. The mitotic serine/threonine kinase Aurora2/AIK is regulated by phosphorylation and degradation. Oncogene 2000;19:4906-16.

[30] Sugiyama K, Sugiura K, Hara T, Sugimoto K, Shima H, Honda K, et al. Aurora-B associated protein phosphatases as negative regulators of kinase activation. Oncogene 2002;21:3103-11.

[31] Hauf S, Cole RW, LaTerra S, Zimmer C, Schnapp G, Walter R, et al. The small molecule Hesperadin reveals a role for Aurora B in correcting kinetochoremicrotubule attachment and in maintaining the spindle assembly checkpoint. J Cell Biol 2003;161:281-94.

[32] Ditchfield C, Johnson VL, Tighe A, Ellston R, Haworth C, Johnson T, et al. Aurora B couples chromosome alignment with anaphase by targeting BubR1, Mad2, and CenpE to kinetochores. J Cell Biol 2003;161:267-80.

[33] Marumoto T, Honda S, Hara T, Nitta M, Hirota T, Kohmura E, et al. Aurora-A kinase maintains the fidelity of early and late mitotic events in HeLa cells. J Biol Chem 2003;278:51786-95.

[34] Yasui Y, Urano T, Kawajiri A, Nagata K, Tatsuka M, Saya H, et al. Autophosphorylation of a newly identified site of Aurora-B is indispensable for cytokinesis. J Biol Chem 2004;279:12997-3003.

[35] Leung-Pineda V, Ryan CE, Piwnica-Worms H. Phosphorylation of Chk1 by ATR is antagonized by a Chk1-regulated protein phosphatase 2A circuit. Mol Cell Biol 2006;26:7529-38.

[36] Westermarck J, Li SP, Kallunki T, Han J, Kahari VM. p38 mitogen-activated protein kinase-dependent activation of protein phosphatases 1 and 2A inhibits MEK1 and MEK2 activity and collagenase 1 (MMP-1) gene expression. Mol Cell Biol 2001;21:2373-83.

[37] Wu Y, Song P, Xu J, Zhang M, Zou MH. Activation of protein phosphatase 2A by palmitate inhibits AMP-activated protein kinase. J Biol Chem 2007;282:9777-88.

[38] Yokoyama N, Miller WT. Protein phosphatase 2A interacts with the Src kinase substrate p130(CAS). Oncogene 2001;20:6057-65.

[39] Zhu X, Kim JL, Newcomb JR, Rose PE, Stover DR, Toledo LM, et al. Structural analysis of the lymphocyte-specific kinase Lck in complex with non-selective and Src family selective kinase inhibitors. Structure 1999;7:651-61.

[40] Law SF, O'Neill GM, Fashena SJ, Einarson MB, Golemis EA. The docking protein HEF1 is an apoptotic mediator at focal adhesion sites. Mol Cell Biol 2000;20:5184-95.

[41] Kang TH, Park DY, Choi YH, Kim KJ, Yoon HS, Kim KT. Mitotic histone H3 phosphorylation by vaccinia-related kinase 1 in mammalian cells. Mol Cell Biol 2007;27:8533-46.

[42] Niiya F, Tatsumoto T, Lee KS, Miki T. Phosphorylation of the cytokinesis regulator ECT2 at G2/M phase stimulates association of the mitotic kinase Plk1 and accumulation of GTP-bound RhoA. Oncogene 2006;25:827-37.

[43] Pugacheva EN, Golemis EA. HEF1-aurora A interactions: points of dialog between the cell cycle and cell attachment signaling networks. Cell Cycle 2006;5:384-91.

\section{Abbreviations}


HEF1, human enhancer of filamentation 1; FAK, focal adhesion kinase; CrkL, Crk-like; PP, protein phosphatase; Cas, Crk associated substrate; SH, Src homology; APC, anaphase promoting complex.

\section{Figure legends}

\section{Fig. 1 HEF1 is differentially expressed in cells}

Cell lysates of different cell lines, containing an equal amount of proteins, were analyzed by western-blotting with a monoclonal anti-HEF1 antibody. Membrane was stripped and reprobed with anti-Hsp90 antibody as a loading control.

\section{Fig. 2 Okadaic acid induces serine/threonine phosphorylation of HEF1}

(A) HCT-116 cells were transiently transfected with pCMV-Flag-HEF1 wt (HEF1 wt) or empty pCMV-Flag (-). Time-course with okadaic acid (OA) at final concentration of $125 \mathrm{nM}$ was performed. Proteins were separated by SDS-PAGE (acrylamide/bisacrylamide ratio of 30:0.2) and analyzed by immunoblotting with anti-Flag antibody. a,b,c refered to different HEF1 isoforms (see description in the text). (B) HCT-116 cells transiently transfected with wild type HEF1 were stimulated for 8 hours with OA (125 nM). Cells lysates containing an equal amount of proteins were immunoprecipitated with anti-Flag antibody. Immunoprecipitates were treated or not with CIAP (calf intestinal alkaline phosphatase) and immunoblotted with anti-Flag antibody.

\section{Fig. 3 HEF1 is phosphorylated in vivo by a Hesperadin-sensitive kinase}

HCT-116 cells were transiently transfected with pCMV-Flag-HEF1 wt (HEF1 wt). Cells were incubated for 8 hours with OA $(125 \mathrm{nM})$ or Hesperadin $(\mathrm{Hes})(1 \mu \mathrm{M})$ or both. HEF1 
migration pattern was revealed by immunoblotting with anti-Flag antibody. Membrane was stripped and reprobed with anti-BubR1 antibody to visualize the activity of Aurora-B.

\section{Fig. 4 Hesperadin-sensitive kinase phosphorylates HEF1 on serine 369}

(A) HCT-116 cells were transiently transfected with pCMV-Flag-HEF1 wt or mutated plasmids, then stimulated or not with OA $(125 \mathrm{nM})$ for 8 hours. Lysates were analyzed by western-blotting with anti-Flag antibody. Lane 1 corresponds to cells transfected with pCMVFlag-HEF1 wt (HEF1 wt), lane 2 with pCMV-Flag-HEF1 S369A (S369A), lane 3 with pCMV-Flag-HEF1 S296A (S296A) and lane 4 with pCMV-Flag-HEF1 S296/369A (S296/369A). a,b,c,d refered to different HEF1 isoforms. Asterisk in lane 3 indicates the position of band d. (B) HCT-116 cells were transiently transfected with pCMV-Flag-HEF1 S369A (S369A) or pCMV-Flag-HEF1 S296A (S296A), then stimulated by OA (125 nM) or Hes $(1 \mu \mathrm{M})$ or both. Immunoblotting was performed with anti-Flag antibody. a,b,d refered to different HEF1 isoforms.

\section{Fig. 5 HEF1 stability is modulated through phosphorylation of serine 369}

(A) HCT-116 cells were transiently transfected with pCMV-Flag-HEF1 wt (HEF1 wt). Timecourse was performed with cycloheximide $(\mathrm{CHX})$ at $70 \mu \mathrm{M}$ alone or with Hes $(1 \mu \mathrm{M})$. Western-blot analysis of cells extracts were performed using anti-Flag antibody. Membranes were probed with anti-Hsp90 antibody to check for equal protein loading. Amounts of proteins were quantified by densitometric analysis: the HEF1 signal was normalized to the Hsp90 signal and, to facilitate comparison, results were expressed as $\%$ of the initial amount (set at 100\%) of HEF1 wt in the presence or not of Hes. (B) HCT-116 cells were transiently transfected with either pCMV-Flag-HEF1 S296A (S296A), pCMV-Flag-HEF1 S369A 
(S369A) or pCMV-Flag-HEF1 S296/369A (S296/369A). Time-course with CHX (70 $\mu \mathrm{M})$ was performed and lysates were resolved by immunoblotting with anti-Flag antibody.

Fig. 6 Phosphorylation of HEF1 on serine 369 induces its proteasomal degradation (A) HCT-116 cells were transiently transfected with pCMV-Flag-HEF1 wt (HEF1 wt). Timecourse with CHX $(70 \mu \mathrm{M})$ was performed in presence of Mg-132 $(10 \mu \mathrm{M})$. Western-blotting was performed using anti-Flag antibody. Membrane was reprobed with anti-Hsp90 antibody as loading control. (B) HCT-116 cells transiently transfected with pCMV-Flag-HEF1 wt (HEF1 wt) were treated for 8 hours with Mg-132 $(10 \mu \mathrm{M})$ or Hes $(1 \mu \mathrm{M})$ or both. Cells lysates containing an equal amount of proteins were immunoprecipitated with anti-Flag antibody. The immunoprecipitated protein complexes were then analyzed by western-blotting with anti-Flag antibody. Asterisk in lane 2 indicates the position of the band similar to band d.

(C) HCT-116 cells were transiently transfected with either pCMV-Flag-HEF1 wt (HEF1 wt), pCMV-Flag-HEF1 S369A (S369A), pCMV-Flag-HEF1 S296A (S296A) or pCMVFlag-HEF1 S296/369A (S296/369A). Cells were treated with OA (125 nM) alone or in combination with Mg-132 $(10 \mu M)$ for 8 hours. Cell lysates were processed for immunoblotting with the anti-Flag antibody (left panel) and the anti-PhosphoSer369HEF1 antibody (right panel) sequentially.

Fig. 7 Endogenous HEF1 is stabilized by Hesperadin treatment

Time-course of $70 \mu \mathrm{M}$ CHX treatment (A) or $1 \mu \mathrm{M}$ Hes treatment (B) or $10 \mu \mathrm{M} \mathrm{Mg}-132$ treatment $(\mathbf{C})$ were performed on HaCaT cells. HEF1 isoforms were resolved using SDSPAGE migration and subsequent hybridization with monoclonal anti-HEF1 antibody.

Membranes were reprobed with anti-Hsp90 antibody to ensure equal protein loading.

Fig. 8 Aurora-B kinase is not involved in HEF1 ser-369 phosphorylation 
$(\mathbf{A}, \mathbf{B}) \mathrm{HaCaT}$ cells were transfected with siRNA targeting Aurora-A or Aurora-B at various concentrations as described. HEF1 isoforms were resolved using SDS-PAGE migration and subsequent hybridization with monoclonal anti-HEF1 antibody. Membranes were reprobed with anti-Hsp90 antibody to ensure equal protein loading and with anti-Aurora-A or antiAurora-B antibody to assess siRNA efficiency. (B) HaCaT cells were transfected with siRNA as described in $\mathrm{A}$ and treated with Nocodazole $(300 \mathrm{nM})$ for $16 \mathrm{~h}$ before harvesting. Membrane was stripped and reprobed with anti-BubR1 antibody to visualize the activity of Aurora-B. (C) Cells were treated with Nocodazole $(300 \mathrm{nM})$ for $16 \mathrm{~h}$ and with Hes $(1 \mu \mathrm{M})$ or ZM $(10 \mu \mathrm{M})$ for 8 hours before harvesting. HEF1 and BubR1 isoforms were resolved using SDS-PAGE migration and subsequent hybridization with monoclonal anti-HEF1 and antiBubR1 antibodies respectively. Membranes were reprobed with anti-Hsp90 antibody to ensure equal protein loading. (D) HaCaT cells were treated with the indicated drugs as described in Materials and Methods. HEF1 shift of migration was revealed using an antiHEF1 antibody. Hsp90 was used as a loading control. 
A - $\quad$ HEF1 wt

OA (h)

0

WB : Flag

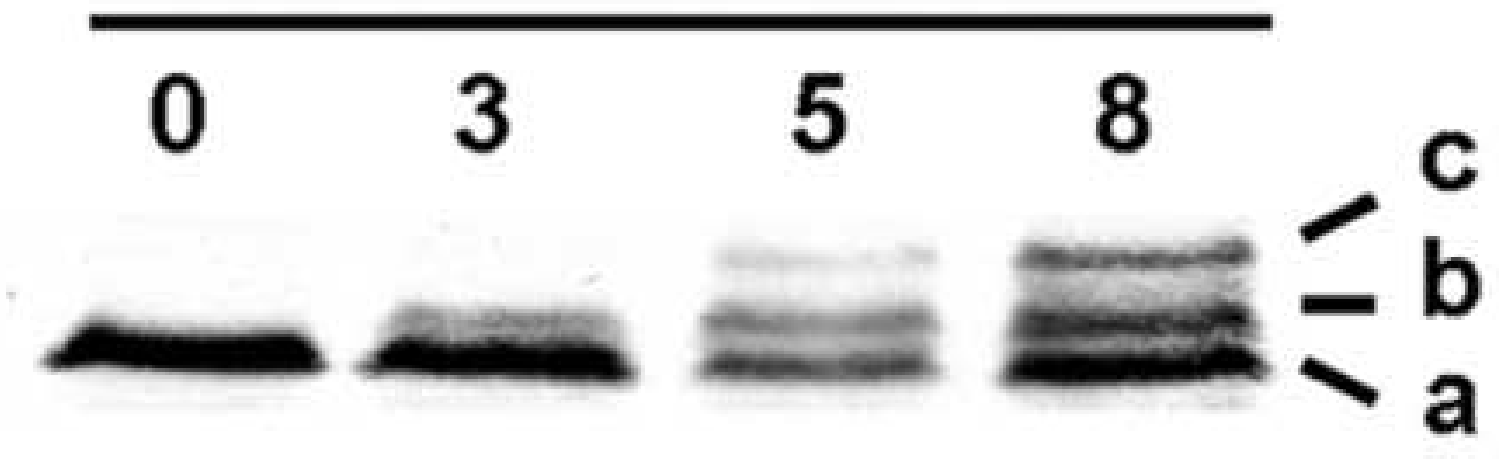

B

OA

CIAP

$+$

IP : Flag

WB : Flag

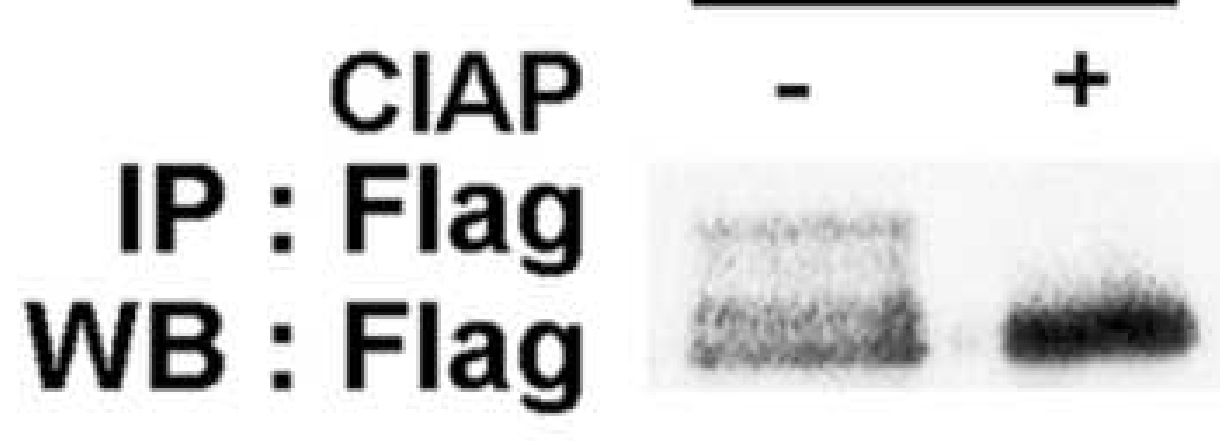

\section{Page 30 of 37}




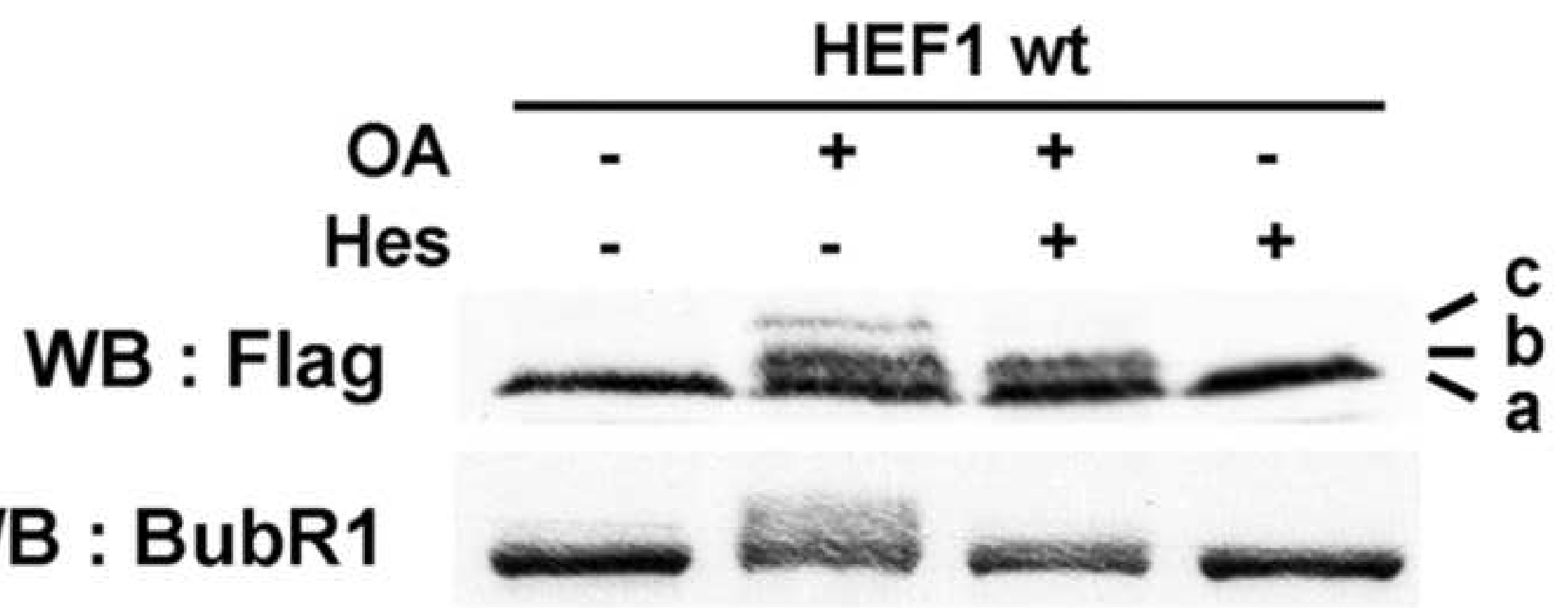

\section{WB : BubR1}

HEF1 wt

$\div a$

37

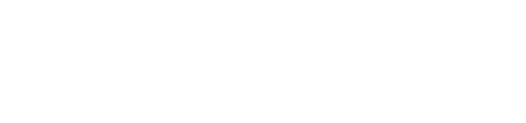

(

(n) 
A

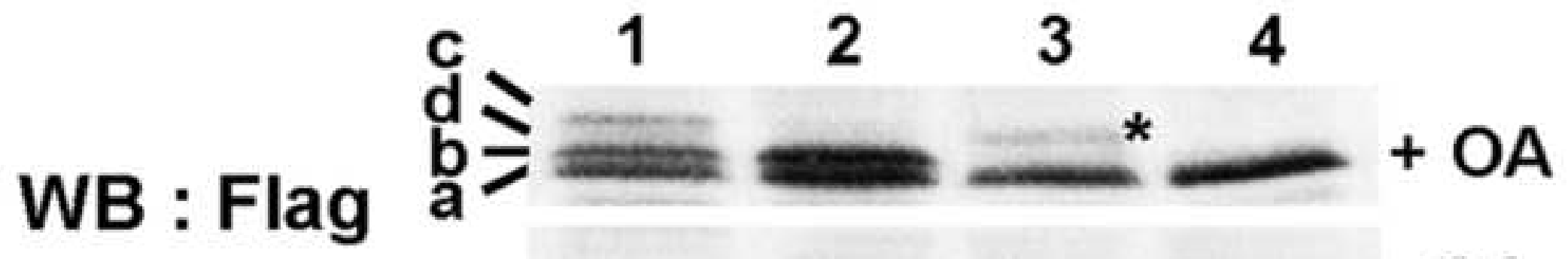
$\longrightarrow--O A$

B

OA

$+$

$+\quad-$

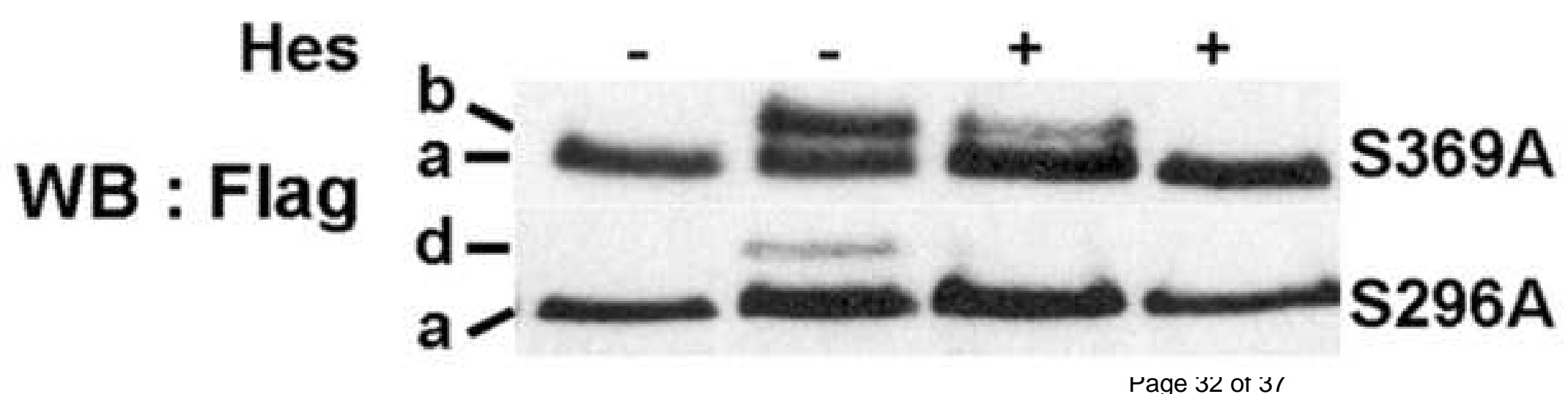

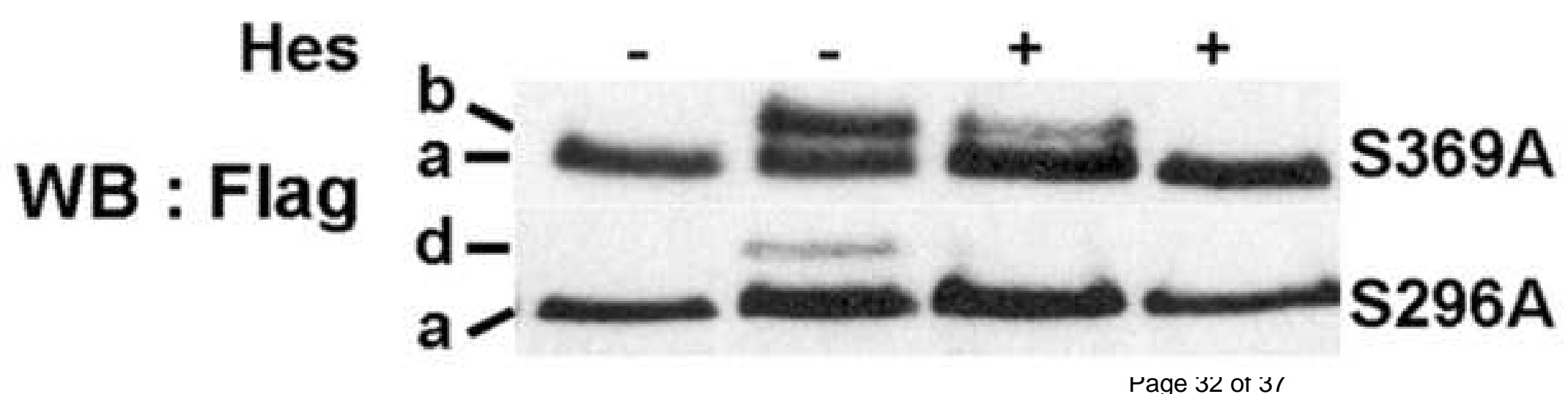

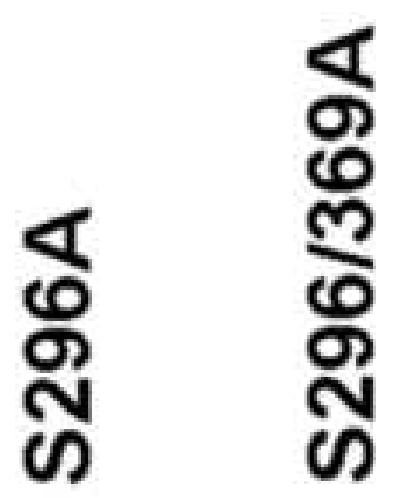


A

HEF1 wt

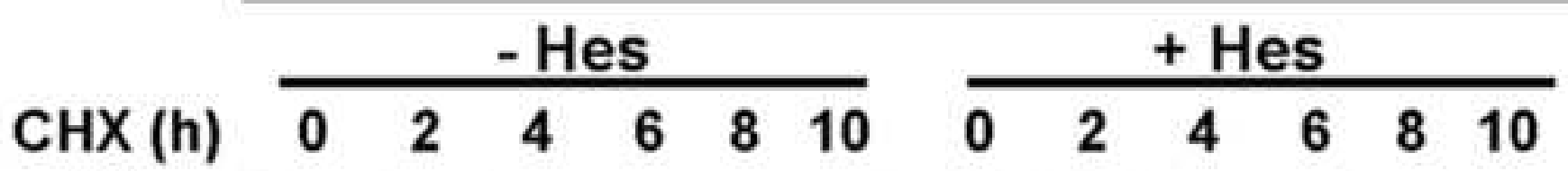

Flag rem-

Hsp90

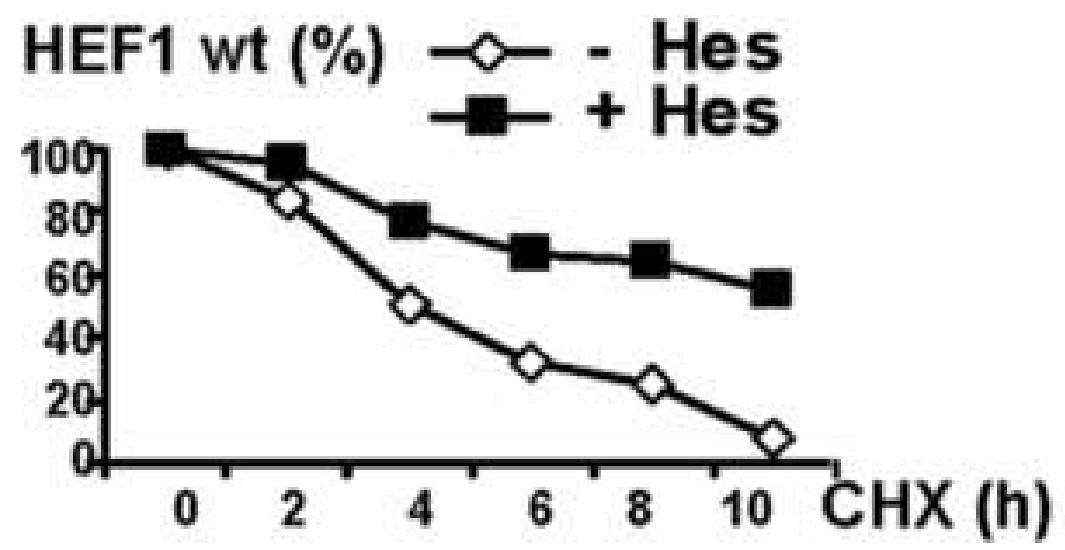

B

$\mathrm{CHX}$ (h)

Flag

Hsp90
S296A

\begin{tabular}{llllll}
\hline 0 & 2 & 4 & 6 & 8 & 10
\end{tabular}

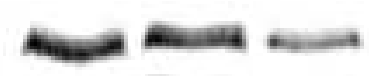

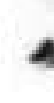

HEF1 (\%)

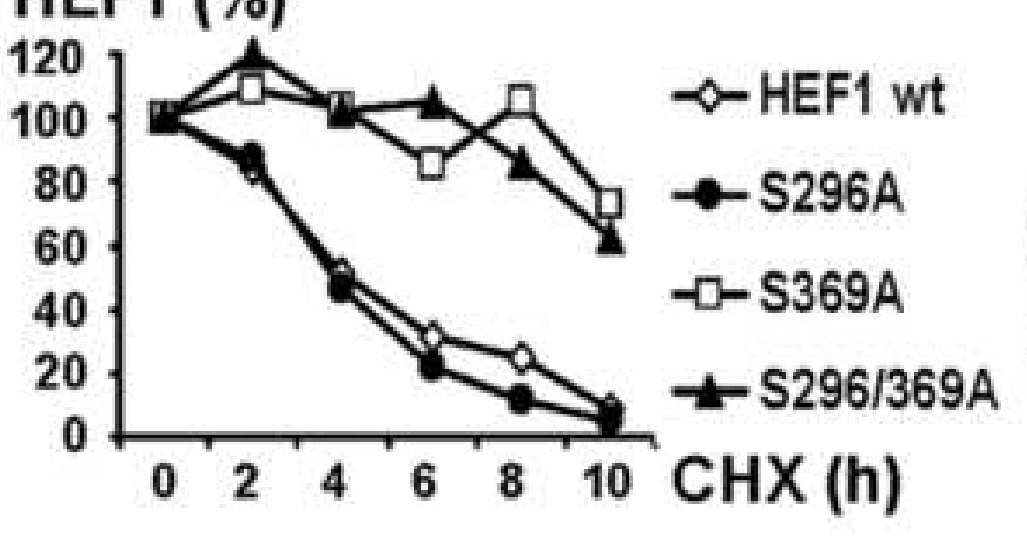

\section{S296/369A}

\begin{tabular}{llllll}
\hline 0 & 2 & 4 & 6 & 8 & 10
\end{tabular}

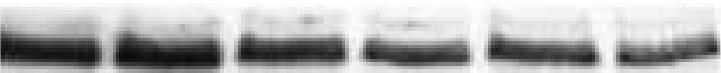


A

$\begin{array}{lllllll}\mathrm{CHX}+\mathrm{Mg}-132 \text { (h) } & 0 & 2 & 4 & 6 & 8 & 10\end{array}$

WB : Flag —- - -

WB : Hsp90
B

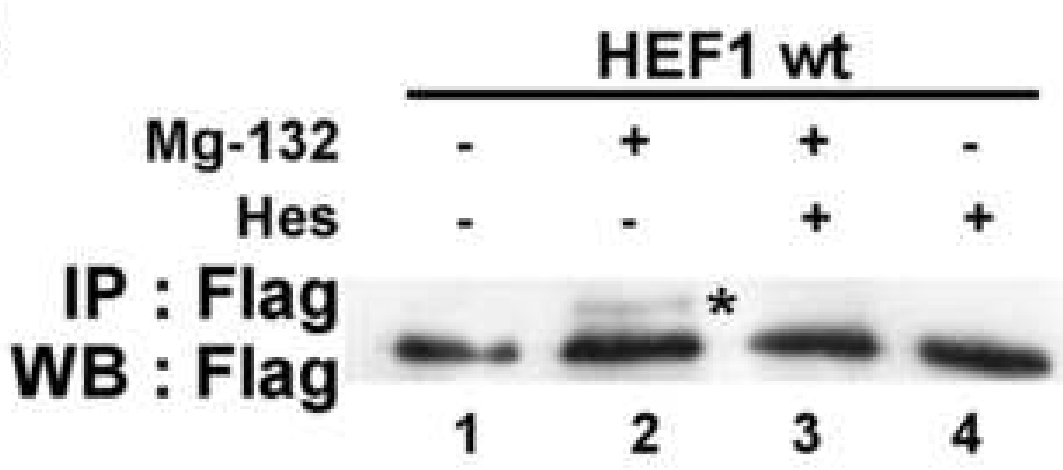

C

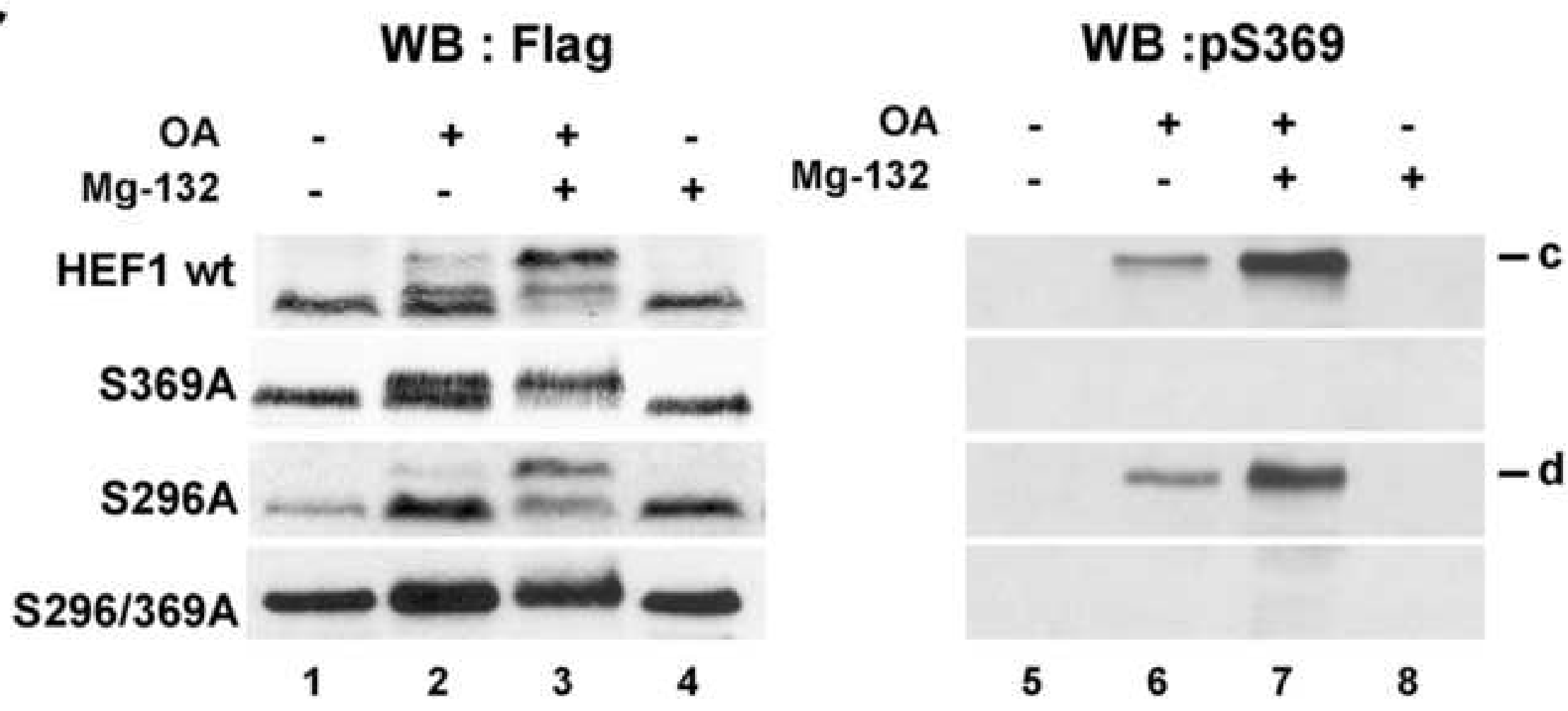



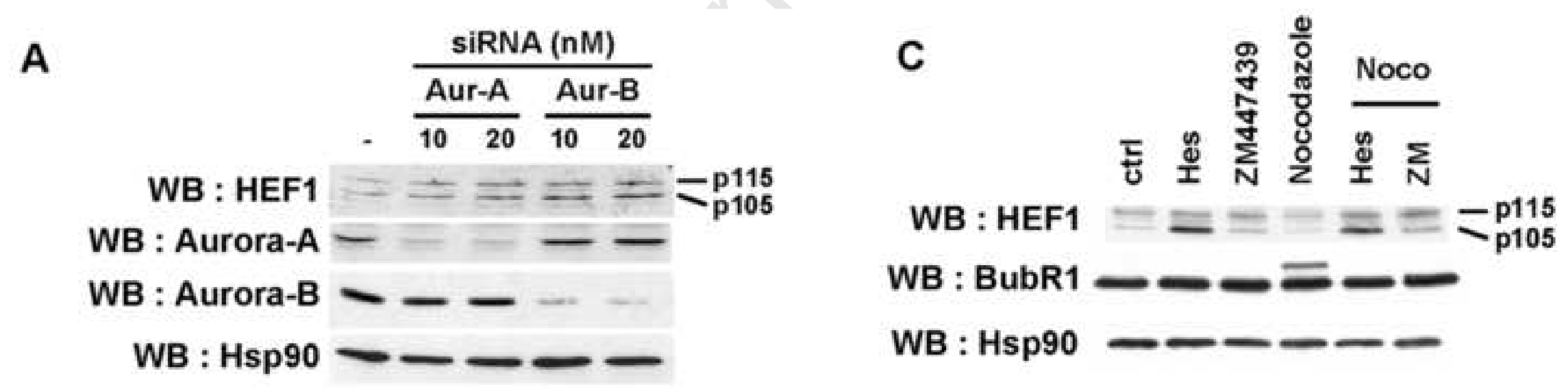

$\begin{array}{rr}\text { siRNA }(20 \mathrm{nM}) & \text { Scr } \\ \text { Nocodazole } & \frac{\text { Aur-B }}{-+} \\ \text { WB : BubR1 } & -=- \\ \text { WB : Aurora-B } & - \\ \text { WB : Hsp90 } & --\end{array}$

D

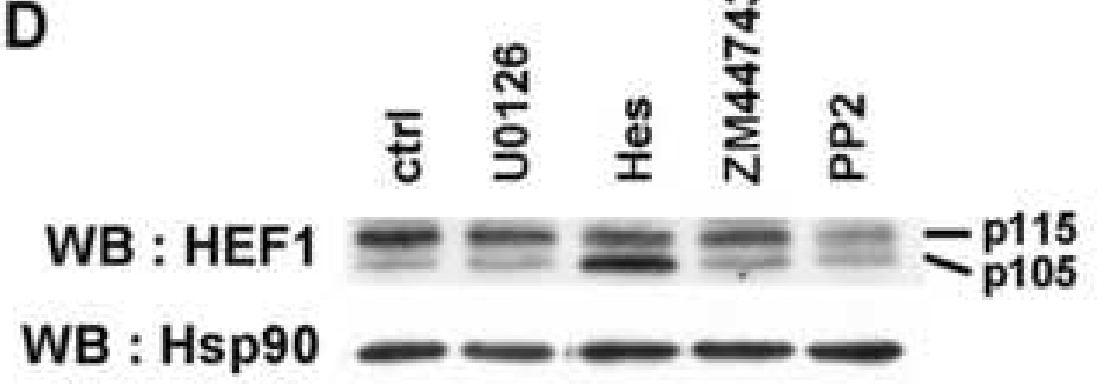


Phosphorylation of HEF1 on ser369 by an Hesperadin-sensitive kinase induces its degradation by the proteasome

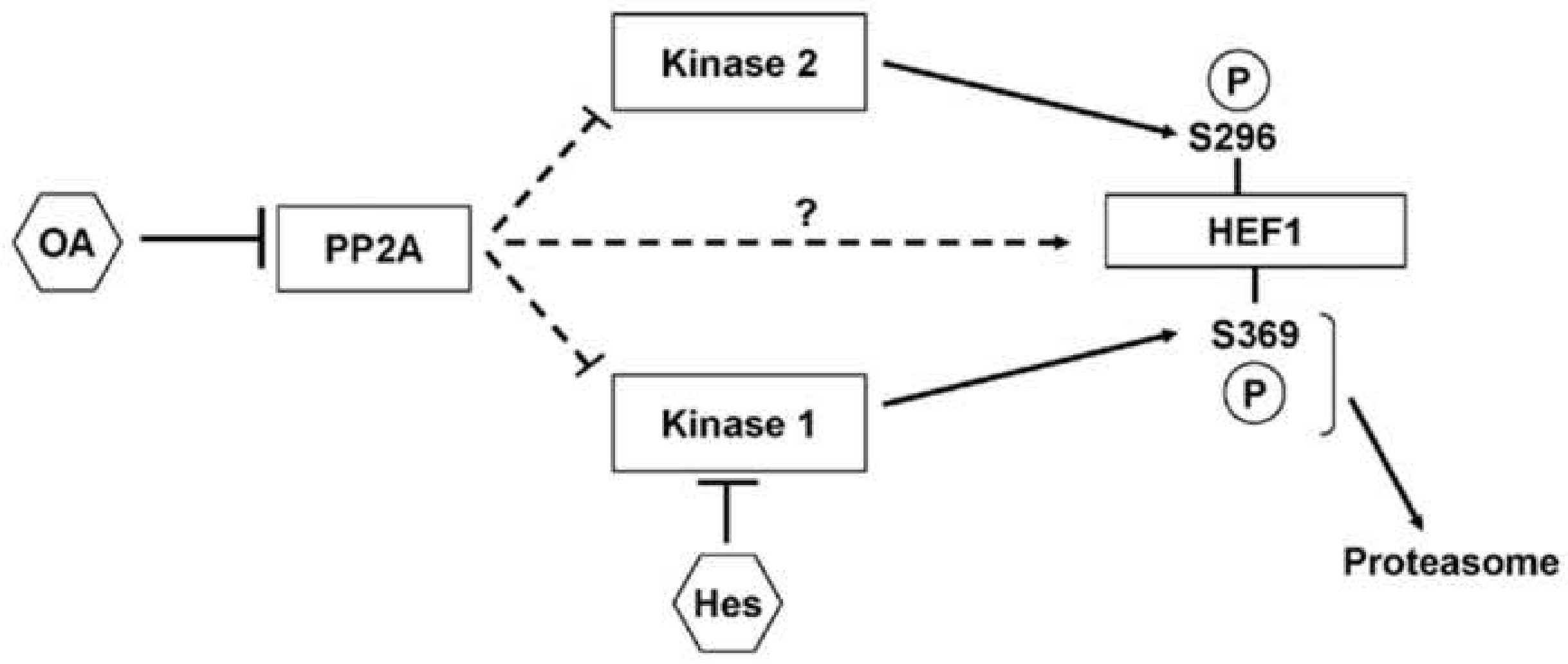

